\title{
Interleukin-1 receptor antagonist in pleural effusion due to inflammatory and malignant lung disease
}

\author{
H. Yanagawa, S. Yano, T. Haku, Y. Ohmoto, S. Sone
}

Interleukin-1 receptor antagonist in pleural effusion due to inflammatory and malignant lung disease. H. Yanagawa, S. Yano, T. Haku, Y. Ohmoto, S. Sone. CERS Journals Ltd 1996.

ABSTRACT: Interleukin (IL)-1 is a key cytokine in inflammatory reactions. To clarify the mechanism of inflammation in the pleural cavity, we investigated the contribution of IL-1 and its antagonism to inflammatory processes in the pleural cavity.

Interleukin-1 receptor antagonist (IL-1Ra) levels as well as IL-1 $\beta$ and interferon$\gamma($ IFN $-\gamma)$ levels were measured by enzyme immunoassay in pleural effusions from 70 patients. Pleural macrophages were also examined as possible sources of these cytokines in 10 patients.

IL-1Ra was detectable in 28 patients $(40 \%)$ out of 70 patients with pleural effusions. Patients with tuberculosis had significantly higher IL-1Ra as well as IFN- $\gamma$ levels in pleural effusion than patients with lung cancer. Transudative pleural effusions had low or undetectable IL-1Ra levels. On the other hand, IL-1 $\beta$ levels were low, except in cases of parapneumonic pleural effusion. Spontaneous production of IL-1Ra by pleural macrophages was observed in six patients, and IL-4 significantly augmented its production. Although spontaneous production of IL-1 $\beta$ was observed in only two patients, pleural macrophages produced significant amounts of IL-1 $\beta$ in response to lipopolysaccharide in all 10 patients examined.

These results suggest that interleukin-1 receptor antagonist regulates various reactions by interleukin-1 in pleural effusion, and that pleural macrophages may act in situ as a source of interleukin-1 receptor antagonist.

Eur Respir J., 1996, 9, 1211-1216.
Third Dept of Internal Medicine, The University of Tokushima School of Medicine, Tokushima, Japan.

Correspondence: H. Yanagawa

Third Dept of Internal Medicine

University of Tokushima School of Medicine Kuramoto-cho 3

Tokushima

770 Japan

Keywords: Interleukin-1 receptor antagonist interleukin-4

pleural effusion

pleural macrophages

tuberculous pleurisy

Received: July 191995

Accepted after revision March 1996

Supported by a Grant-in-Aid for Scientific Research from the Ministry of Education, Science and Culture of Japan.
Interleukin (IL)-1 is a cytokine with pleiotropic effects, including initiation of the inflammatory response, and its production and biological activity is strictly regulated [1]. Since pleural effusions develop in association with pleural inflammation secondary to pulmonary and/or systemic disease [2], the evaluation of the in situ production of IL-1 and its antagonism may help to clarify the inflammatory process in the pleural cavity. Of the two forms in which IL-1 exists, IL-1 $\beta$ is the major extracellular form in humans [1], and the presence of IL-1 $\beta$ in pleural effusion has been reported [3]. However, there is still little information about endogenous interleukin-1 receptor antagonist (IL-1Ra), a naturally occurring cytokine that blocks the action of IL-1 [4, 5], in pleural effusion.

IL-1Ra was originally identified as a product from blood monocytes [6, 7], and we [8] and others $[9,10]$ have demonstrated that alveolar macrophages also produce this cytokine. On the other hand, pleural macrophages may act as another cellular source of IL-1Ra in pleural effusion; however, nothing is known about the ability of pleural macrophages to produce IL-1Ra.

In the present study, we investigated the presence of IL-1Ra and IL-1 $\beta$ in pleural effusion due to various diseases, and also the in vitro production of these cytokines by pleural macrophages.

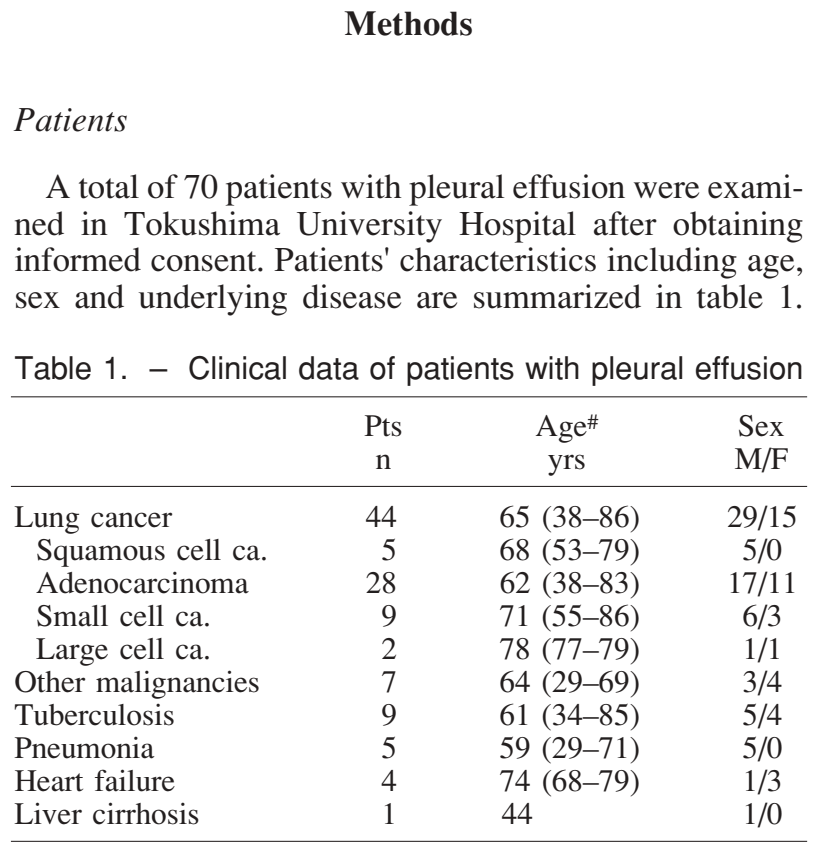

\#: values are mean, and range in parenthesis. Pts: patients; M: male; F: female; ca.: carcinoma. 
Malignant pleural effusion was diagnosed by pleural effusion cytology. Forty four patients with lung cancer and seven patients with other malignancies (two lymphomas, one gastric cancer, one breast cancer, one malignant thymoma, and two diffuse pleural mesotheliomas) were examined. Tuberculous pleurisy $(n=9)$ was defined by positive culture of Mycobacterium tuberculosis from pleural effusion or histological findings in a pleural biopsy specimen. Pleural effusions secondary to congestive heart failure ( $\mathrm{n}$ $=4)$ or liver cirrhosis $(n=1)$ were defined as transudative effusions in patients with clinical signs and symptoms of these diseases.

\section{Sampling of pleural effusions and storage}

Pleural effusion was collected via diagnostic thoracentesis. After centrifugation at $400 \times \mathrm{g}$ for $10 \mathrm{~min}$, cell-free supernatant was separated and stored at $-70^{\circ} \mathrm{C}$ until assayed for cytokines.

\section{Reagents}

Foetal bovine serum (FBS) was purchased from M.A. Bioproducts (Walkerville, MD, USA). Recombinant human IL-4 (lot 801; specific activity $1.0 \times 10^{6} \mathrm{U} \cdot \mathrm{mg}^{-1}$ protein) was a gift from Ono Pharmaceutical Co., Osaka, Japan. None of these materials contained endotoxins, as judged by Limulus amoebocyte assay (Seikagaku Kogyo Co., Tokyo, Japan; minimal detection level $\left.0.3 \mathrm{ng} \cdot \mathrm{mL}^{-1}\right)$. Lipopolysaccharide (LPS); (E. coli; 055.B5) was purchased from Difco Laboratories.

\section{Isolation of pleural macrophages}

Pleural macrophages were isolated essentially by the method of COLOTTA et al. [11], as described previously [12], from pleural effusion samples obtained from 10 patients. In brief, mononuclear cells were separated from pleural effusion using lymphocyte separation medium (Litton Bionetics, Kensington, MD, USA). Fractions of pleural macrophages $(>85 \%)$ were separated from the mononuclear cells by a one-step Percoll gradient method. Nonadherent cells were removed $1 \mathrm{~h}$ after plating by gentle washing.

\section{In vitro activation}

Monolayers of pleural macrophages $\left(1 \times 10^{6} \cdot \mathrm{mL}^{-1}\right)$ were incubated for $24 \mathrm{~h}$ at $37^{\circ} \mathrm{C}$ in RPMI 1640 medium supplemented with $5 \%$ heat-inactivated FBS and gentamicin with or without $100 \mathrm{U} \cdot \mathrm{mL}^{-1}$ of IL-4 or $1 \mu \mathrm{g} \cdot \mathrm{mL}^{-1}$ of LPS. The cell-free supernatants were then collected after brief centrifugation at $50 \times \mathrm{g}$. IL-4 and LPS at these concentrations were chosen as potential stimulatory agents because of their ability to induce production of IL-1Ra in human monocytes and alveolar macrophages as described previously [8].

Enzyme immunoassay (EIA) for human IL-1Ra, IL-1 $\beta$ and interferon(IFN)- $\gamma$

EIA of human IL-1Ra, IL-1 $\beta$ and IFN- $\gamma$ was performed essentially as described previously [8]. In brief, microtitre plates (Nunc, Naperville, IL, USA) were coated with antiIL-1Ra, anti-IL-1 $\beta$ or anti-IFN- $\gamma$ monoclonal antibody in phosphate-buffered saline (PBS) $\left(100 \mu \mathrm{L} \cdot\right.$ well $\left.^{-1}\right)$. After overnight incubation at $4^{\circ} \mathrm{C}$, the wells were blocked with $0.1 \%$ bovine serum albumin (BSA) in PBS and washed three times. Volumes of $200 \mu \mathrm{L}$ of each test sample were added to duplicate wells. The plates were then incubated at $37^{\circ} \mathrm{C}$ for $24 \mathrm{~h}$. After washing, $100 \mu \mathrm{L}$ of rabbit antiIL-1Ra, anti-IL-1 $\beta$ or anti-IFN- $\gamma$ antibody was added to each well. The plates were then incubated for $2 \mathrm{~h}$ at $37^{\circ} \mathrm{C}$, washed three times, supplemented with $100 \mu \mathrm{L}$ of peroxidase-labelled goat anti-rabbit immunoglobulin $\mathrm{G}$ $(\mathrm{IgG})(\mathrm{H}+\mathrm{L})$ (Zymed Laboratories, San Francisco, CA, USA) and incubated at room temperature for $2 \mathrm{~h}$. Finally, the plates were washed five times, and $100 \mu \mathrm{L}$ of enzyme substrate $\left(1 \mathrm{mg} \cdot \mathrm{mL}^{-1} \mathrm{o}\right.$-phenylenediamine (OPD) in 0.1 $\mathrm{M}$ sodium citrate buffer, $\mathrm{pH}$ 5.0) was added to each well. The plates were then incubated at room temperature for $5 \mathrm{~min}$. The reaction was stopped by adding $100 \mu \mathrm{L}$ of sulphuric acid to each well, and the absorbance at 492 $\mathrm{nm}$ was measured using a Titertek Multiscan. Sensitivity limits of the EIA for IL-1Ra, IL- $1 \beta$ and IFN- $\gamma$ were 0.2 $\mathrm{ng} \cdot \mathrm{mL}^{-1}, 20 \mathrm{pg} \cdot \mathrm{mL}^{-1}$ and $20 \mathrm{pg} \cdot \mathrm{mL}^{-1}$, respectively, and lower levels were considered undetectable.

\section{Measurement of total protein levels in pleural effusions}

Total protein levels in pleural effusion were measured by the pyrogallol red method [13] as a routine examination in our hospital.

\section{Statistical analysis}

Results of experiments were expressed as mean \pm SEM. The statistical significance of differences between groups was analysed using Student's t-test (two-tailed). Data were considered statistically significant if p-values were less than 0.05 .

\section{Results}

\section{Levels of IL-1Ra in pleural effusion}

Out of 70 patients with pleural effusions, 28 (40\%) had detectable IL-1Ra in their pleural effusion. As shown in figure 1, patients with tuberculosis had significantly higher IL-1Ra levels in pleural effusion $\left(3.07 \pm 0.62 \mathrm{ng} \cdot \mathrm{mL}^{-1}\right.$; $\mathrm{p}<0.01)$ than patients with lung cancer $\left(0.44 \pm 0.02 \mathrm{ng} \cdot \mathrm{mL}^{-1}\right)$. Patients with parapneumonic pleural effusions had moderate IL-1Ra levels in pleural effusion $\left(1.63 \pm 0.45 \mathrm{ng} \cdot \mathrm{mL}^{-1}\right)$. At the same time, total protein levels in these pleural effusions were also examined. Total protein levels in pleural effusion due to lung cancer, pneumonia and tuberculosis were $4.07 \pm 0.03,3.80 \pm 0.44$ and $4.96 \pm 0.11 \mathrm{~g} \cdot \mathrm{dL}^{-1}$, respectively. Tuberculous pleural effusion had significantly higher total protein levels than pleural effusion due to lung cancer $(\mathrm{p}<0.05)$.

On the other hand, IL-1Ra was barely observed in only one patient $\left(0.23 \mathrm{ng} \cdot \mathrm{mL}^{-1}\right)$ out of five patients with transudative pleural effusions due to congestive heart failure or liver cirrhosis. 


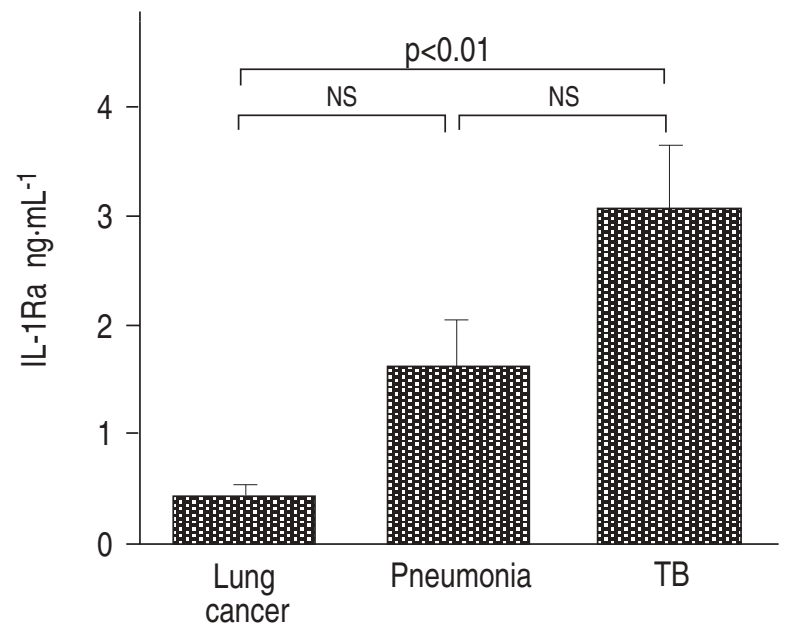

Fig. 1. - Mean and SEM levels of interleukin-1 receptor antagonist (IL-1Ra) in pleural effusion in patients with lung cancer, pneumonia and tuberculosis. NS: not significant; TB: tuberculosis.

The individual data for underlying histology of malignant diseases are shown in figure 2 . IL-1Ra was detected in 4 out of 5 patients $(80 \%)$ with squamous cell carcinoma and in 9 out of 28 patients $(33 \%)$ with adenocarcinoma. Levels of IL-1Ra in the pleural effusion of patients with squamous cell carcinoma $\left(1.56 \pm 0.47 \mathrm{ng} \cdot \mathrm{mL}^{-1}\right)$ were significantly higher than those of patients with adenocarcinoma $\left(0.4 \pm 0.03 \mathrm{ng} \cdot \mathrm{mL}^{-1}\right)(\mathrm{p}<0.05)$. A high IL-1Ra level in pleural effusion $\left(11.74 \mathrm{ng} \cdot \mathrm{mL}^{-1}\right)$ was observed in a patient with diffuse malignant mesothelioma.

\section{Levels of IL-1 $\beta$ and IFN- $\gamma$ in pleural effusion}

The presence of cytokines, such as IL-1 $\beta$ [3] and IFN- $\gamma$ [14], in pleural effusion has been reported. We also examined IL- $1 \beta$ and IFN- $\gamma$ levels in patients with pleural

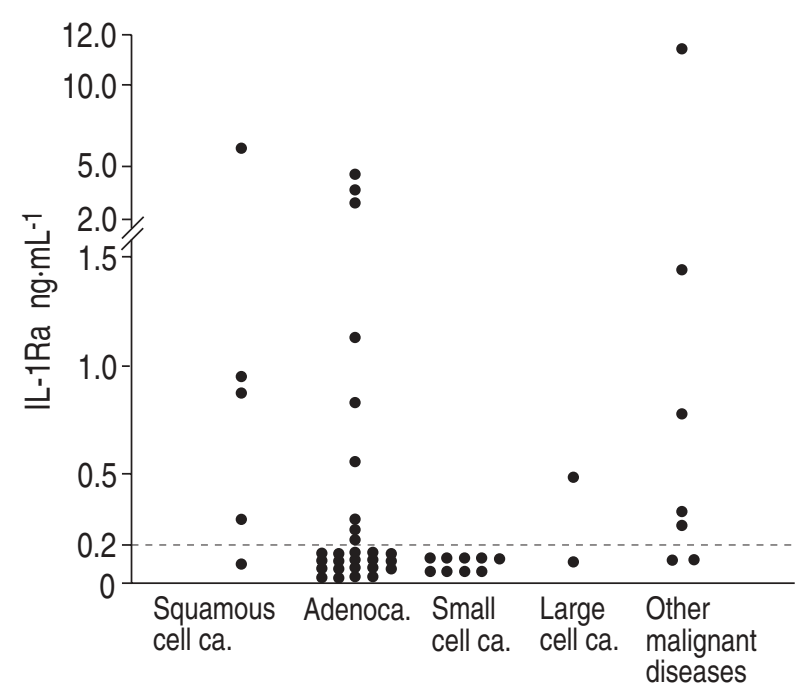

Fig. 2. - Levels of interleukin-1 receptor antagonist (IL-1Ra) in pleural effusion in patients with lung cancer and other malignant diseases. The lower limit of detection for the assay was $0.2 \mathrm{ng} \cdot \mathrm{mL}^{-1}(\ldots-\ldots)$. ca.: carcinoma.

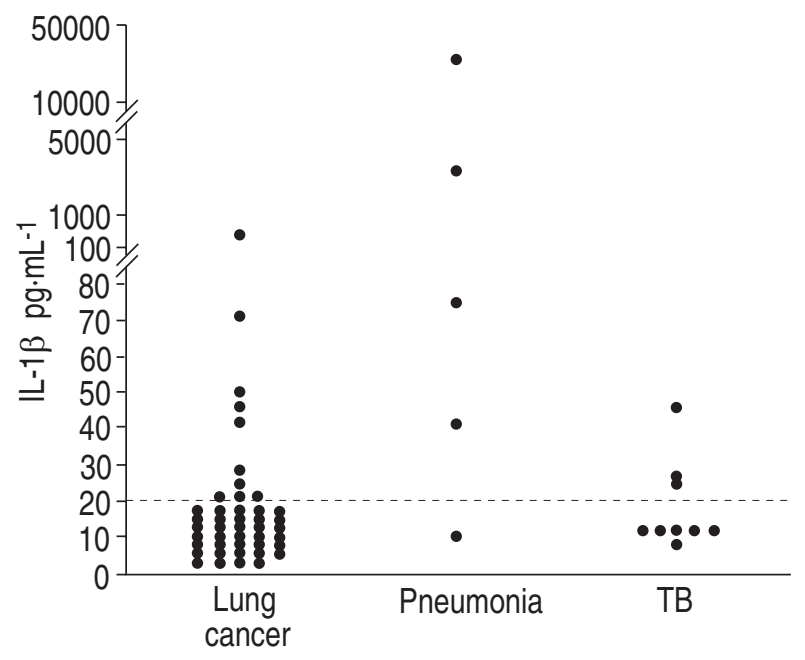

Fig. 3. - Levels of interleukin-1 $\beta$ (IL-1 $\beta$ ) in pleural effusion in patients with lung cancer, pneumonia and tuberculosis. The lower limit of detection for the assay was $20 \mathrm{pg} \cdot \mathrm{mL}^{-1}(\cdots)$. TB: tuberculosis.

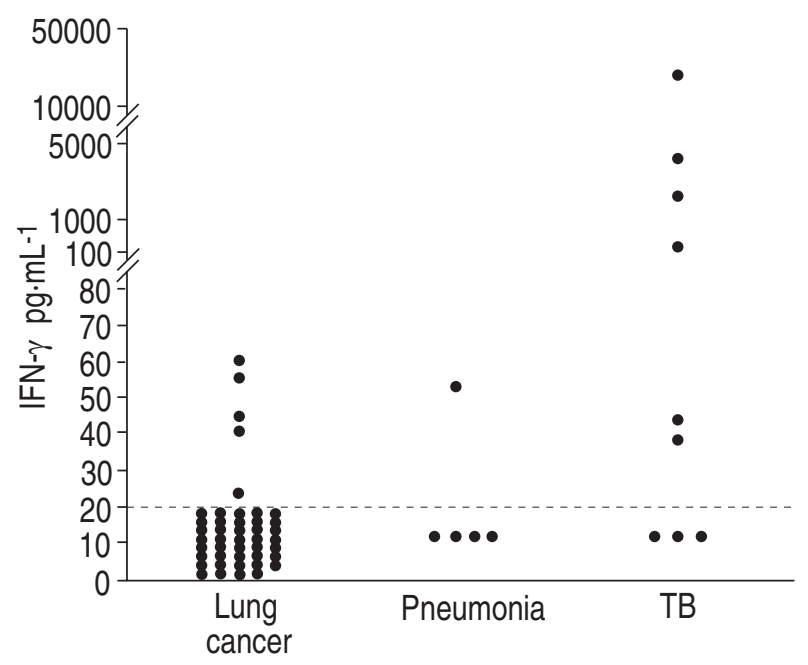

Fig. 4. - Levels of interferon- $\gamma$ (IFN- $\gamma$ ) in pleural effusion in patients with lung cancer, pneumonia and tuberculosis. The lower limit of detection for the assay was $20 \mathrm{pg} \cdot \mathrm{mL}^{-1}(\ldots \ldots)$ TB: tuberculosis.

effusions, in addition to IL-1Ra levels. As shown in figure $3, \mathrm{IL}-1 \beta$ was detectable in 10 out of 44 patients with malignant pleurisy due to lung cancer, and in 3 out of 9 patients with tuberculous pleurisy. The levels of IL-1 $\beta$ in these two groups were low, and mean values were $<20 \mathrm{pg} \cdot \mathrm{mL}^{-1}$. Conversely, four out of five patients with parapneumonic pleural effusion had detectable IL-1 $\beta$ levels, (mean \pm SEM $6.77 \pm 2.68 \mathrm{ng} \cdot \mathrm{mL}^{-1}$ ).

IFN- $\gamma$ levels in pleural effusion are shown in figure 4. IFN- $\gamma$ levels in pleural effusion were significantly higher in patients with tuberculosis than in patients with lung cancer $(\mathrm{p}<0.01)$.

Levels of IL-1 $\beta$ and IFN- $\gamma$ in pleural effusion with or without detectable IL-1Ra levels

To study the possible correlation between the levels of these cytokines, IL- $1 \beta$ and IFN- $\gamma$ levels were examined in pleural effusion with or without detectable pleural 
Table 2. - Levels of IL-1 $\beta$ and IFN- $\gamma$ in pleural effusion in patients with or without detectable IL-1Ra levels in pleural effusion

\begin{tabular}{lll}
\hline & $\begin{array}{c}\mathrm{IL}-1 \beta \\
\mathrm{pg} \cdot \mathrm{mL}^{-1}\end{array}$ & $\begin{array}{c}\mathrm{IFN}-\gamma \\
\mathrm{pg} \cdot \mathrm{mL}^{-1}\end{array}$ \\
\hline $\begin{array}{c}\text { Patients with } \\
\text { detectable IL-1Ra }\end{array}$ & $136 \pm 22$ & $760 \pm 94$ \\
$\begin{array}{c}\text { Patients without } \\
\text { detectable IL-1Ra }\end{array}$ & $814 \pm 131$ & $8.3 \pm 0.81$ \\
\hline
\end{tabular}

Values are presented as mean \pm SEM. IL-1 $\beta$ : interleukin-1 $\beta$; IFN$\gamma$ : interferon- $\gamma$; IL-Ra: interleukin-1 receptor antagonist.

IL-1Ra levels. The results are shown in table 2. In pleural effusion with detectable IL-1Ra levels, IL-1 $\beta$ levels were lower and IFN- $\gamma$ levels were higher than in those without detectable IL-1Ra, but these differences did not reach statistical significance.

Production of IL-1Ra by pleural macrophages and its augmentation by $I L-4$

Since it has been reported that human blood monocytes and alveolar macrophages are cellular sources of IL-1Ra [6-10], the possible production of IL-1Ra by pleural macrophages was examined. Pleural macrophages were obtained from eight patients with exudative pleural effusion (one with squamous cell carcinoma, five with adenocarcinoma, one with small cell carcinoma and one with tuberculosis) and from two patients with transudative pleural effusion due to chronic heart failure. The data are shown in figure 5. Spontaneous production of IL-1Ra by pleural macrophages was observed in six patients. The addition of $100 \mathrm{U} \cdot \mathrm{mL}^{-1}$ of IL-4 significantly augmented IL-1Ra production by pleural macrophages, from $0.88 \pm 0.11$ to $2.25 \pm 0.17 \mathrm{ng} \cdot \mathrm{mL}^{-1}(\mathrm{p}<0.05)$. Conversely, 1 $\mu \mathrm{g} \cdot \mathrm{mL}^{-1}$ of LPS augmented IL-1Ra production in 8 of 10 patients, and suppressed it in the other two patients.

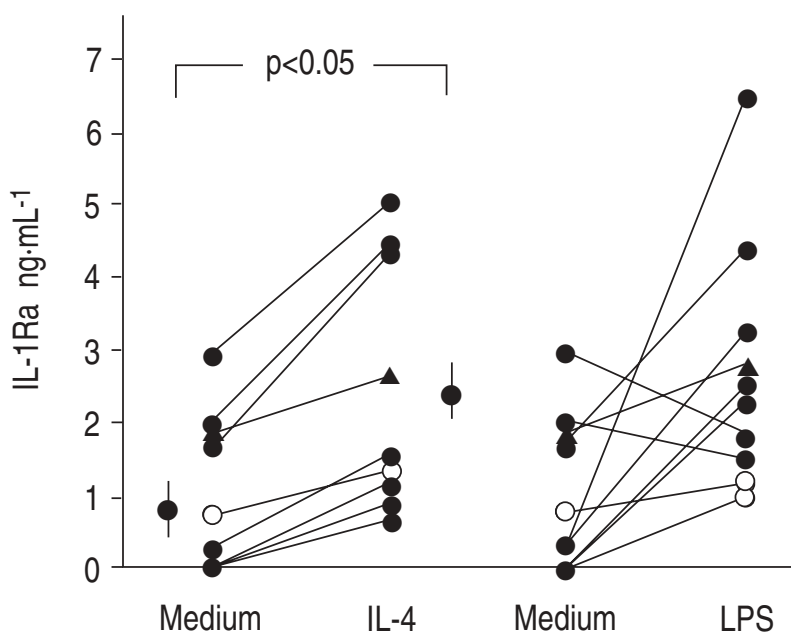

Fig. 5. - Production of IL-Ra by pleural macrophages. Pleural macrophages obtained from patients with lung cancer $(-\bullet)$, tuberculosis $(\boldsymbol{\Delta} \mathbf{\Delta})$ and congestive heart failure $(0-0)$ were incubated for $24 \mathrm{~h}$ with or without $100 \mathrm{U} \cdot \mathrm{mL}^{-1}$ of IL-4 or $1 \mu \mathrm{g} \cdot \mathrm{mL}^{-1}$ of LPS, and the amounts of IL-1Ra released extracellularly were measured by EIA. : mean士SEM. IL-4: interleukin-4; LPS: lipopolysaccharide; IL-1Ra: interleukin-1 receptor antagonist; EIA: enzyme immunoassay.

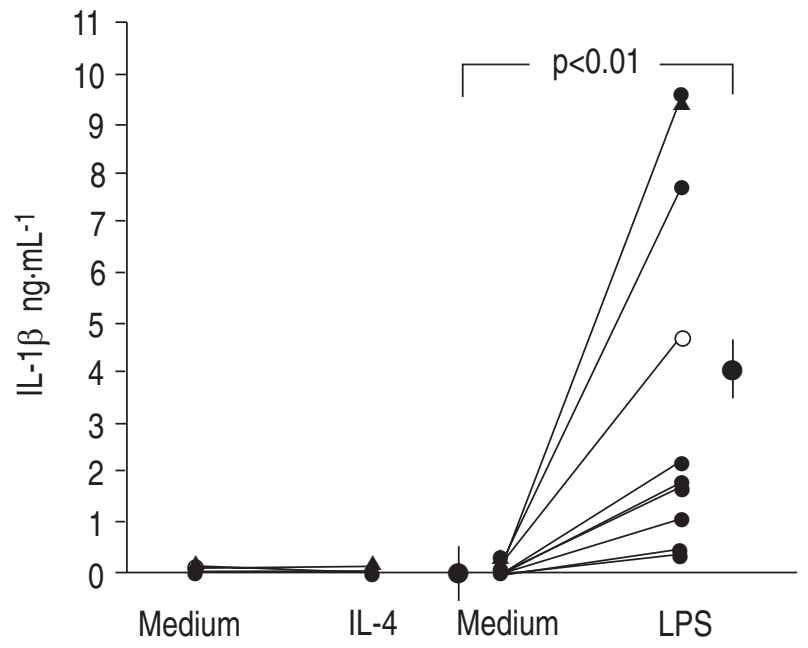

Fig. 6. - Production of interleukin-1 $\beta$ (IL-1 $\beta$ ) by pleural macrophages. Pleural macrophages obtained from patients with lung cancer $(\bullet-\bullet)$, tuberculosis $(\mathbf{\Delta}-\mathbf{\Delta})$ and congestive heart failure $(0-0)$ were incubated for $24 \mathrm{~h}$ with or without $100 \mathrm{U} \cdot \mathrm{mL}^{-1}$ of IL-4 or $1 \mu \mathrm{g} \cdot \mathrm{mL}^{-1}$ of LPS, and the amounts of IL- $1 \beta$ released extracellularly were measured by EIA. mean \pm SEM. For definitions see legend to figure 5 .

\section{Production of IL-1 $\beta$ by pleural macrophages in response to $L P S$}

In a parallel experiment, production of IL-1 $\beta$ by pleural macrophages was examined. Spontaneous production of IL- $1 \beta$ was observed in a patient with tuberculosis and a patient with chronic heart failure. IL-4 had no enhancing effect on production of IL-1 $\beta$ by pleural macrophages, but pleural macrophages from these 10 patients produced significant amounts of IL-1 $\beta$ in response to LPS (fig. 6). LPS-stimulated production of IL-1 $\beta$ had no significant correlation with LPS-stimulated production of IL-1Ra $(\mathrm{p}=0.406)$ (data not shown).

\section{Discussion}

IL-1 is known to be a key cytokine in various immune and inflammatory responses [1]. Among the regulatory factors of IL-1-mediated inflammatory reactions, recent attention has been focused on IL-1Ra, a cytokine that binds IL-1 receptor without any antagonistic activity [4, 5]. IL-1 and IL-1 antagonism may play important roles in the inflammatory process in the pleural cavity, and this is the first demonstration of the presence of IL-1Ra in pleural effusion. Moreover, the present study showed that pleural macrophages are a possible source of IL-1Ra in pleural effusion in the present study.

IL-1Ra was originally reported to be a product of blood monocytes [6, 7]. Since functions of monocyte-macrophages are regulated in different ways depending on the maturation state $[15,16]$, it is of interest to examine the ability of pleural macrophages to produce IL-1Ra and IL1 in order to investigate local inflammatory reactions in the pleural space. The ability of pleural macrophages to produce IL-1 $\beta$ has been reported previously [17]. Since we have already demonstrated that IL-4, as well as LPS, augments spontaneous IL-1Ra production by normal human alveolar macrophages [8], we examined pleural 
macrophages using LPS as a possible activator of cytokine production and IL-4 as a possible activator of IL-1Ra production. To confirm previous reports, we demonstrated that pleural macrophages produced IL- $1 \beta$ in response to LPS (fig. 6). Moreover, as shown in figure 5, pleural macrophages spontaneously produced significant amounts of IL-1Ra in 8 out of 10 patients examined, and IL-4 showed significant augmentation of IL-1Ra production by pleural macrophages. On the other hand, LPS showed up- or down-regulation of IL-1Ra production by pleural macrophages. Recently, KNOPF et al. [18] have reported that LPS augments IL-1Ra production by peritoneal macrophages in cancer patients. These findings suggest that the mechanism of regulation of IL-1Ra production may differ among mature macrophages.

In addition to cells of monocyte-macrophage lineage, various cells are reported to be a source of IL-1Ra. Neutrophils produce IL-1Ra in response to granulocyte/macrophage colony stimulating factor (GM-CSF) and tumour necrosis factor- $\alpha$ (TNF- $\alpha)$ [19]. SмIтH et al. [20] have reported that human bronchogenic carcinoma cells and a cellline, A549, produce IL-1Ra. Considering these previous reports, cancer cells and other host cells may contribute to the levels of IL-1Ra in pleural effusions. Nevertheless, pleural macrophages can also be a significant cellular source of IL-1Ra in pleural effusion.

To investigate the in situ kinetics of IL-1Ra production in pleural effusion, we documented the presence of IL-1Ra in 28 out of 70 patients, and showed that IL-1Ra levels were significantly higher in patients with tuberculosis than in those with lung cancer (fig. 1). At the same time, in accordance with a previous report [21], total protein levels in pleural effusion were significantly higher in patients with tuberculosis than in those with lung cancer.

The cause of elevated levels of IL-1Ra and its role in tuberculous pleurisy are unclear at present, but the contribution of IFN- $\gamma$ should be considered. Elevated levels of IFN- $\gamma$ in tuberculous pleurisy have been reported previously $[3,14]$. IFN- $\gamma$ is supposedly produced by CD4+ lymphocytes in pleural effusion [22,23]. We have already demonstrated that IFN- $\gamma$ augments IL-1Ra production by alveolar macrophages [8]. In accordance with previous reports, IFN- $\gamma$ levels were higher in cases of tuberculous pleurisy than carcinomatous pleurisy due to lung cancer in the present study (fig. 4). Moreover, although no significant difference was observed, IFN- $\gamma$ levels were higher in pleural effusions with detectable IL-1Ra levels than in those without detectable IL-1Ra levels (table 2). High IL-1Ra levels in tuberculous pleural effusion may reflect an IFN- $\gamma$-mediated immune response in tuberculous pleurisy, and IL-1Ra may act as a natural downregulator of the inflammatory response initiated by IFN $-\gamma$. Further study of the effect of antituberculous therapy on IL-1Ra levels in tuberculous pleurisy may provide more information on inflammatory responses in pleural effusion.

The role of IL-1 and IL-1 antagonism in tumour progression has only been partially characterized. ONOZAKI et al. [24] have reported that IL-1 is a cytocidal factor for several tumour cell lines. On the other hand, it has been reported that IL-1 induced an increase in experimental lung metastases, and that IL-1Ra inhibited the augmentation of metastases induced by IL-1 in an animal system [25]. These results suggest a role for IL-1 in metastasis. The present study revealed that levels of IL$1 \mathrm{Ra}$ in pleural effusion were significantly higher in cases of squamous cell carcinoma than in those of adenocarcinoma. Further investigation in carcinomatous pleurisy may provide more information about the possible contribution of IL-1 and IL-1 antagonism to tumour progression and host defence in tumour-bearing state.

In the present study, we have demonstrated that interleukin-1 receptor antagonist is present in pleural effusions. Like interleukin-4, interleukin-10 has been reported to augment production of interleukin-1 receptor antagonist by human monocytes [26]. We have also recently reported that IL-13 augments interleukin-1 receptor antagonist production by human alveolar macrophages [27]. The study of in vivo regulatory mechanisms of production of interleukin-1 receptor antagonist by pleural macrophages, as well as other host cells in various disease states, is warranted for the better understanding of underlying diseases.

Acknowledgements: The authors thank Y. Sakata and $\mathrm{K}$. Murata for their kind help in the measurement of cytokines.

\section{References}

1. Dinarello CA. Interleukin-1 and interleukin-1 antagonism. Blood 1991; 77: 1627-1652.

2. Antony VB, Sahn SA, Mossman B, Gail DB. Pleural cell biology in health and disease: NHLBI workshop summary. Am Rev Respir Dis 1992; 145: 1236-1239.

3. Shimokata K, Saka H, Murate T, Hasegawa Y, Hasegawa T. Cytokine content in pleural effusion: comparison between tuberculous and carcinomatous pleurisy. Chest 1991; 99: 1103-1107.

4. Hannum CH, Wilcox CJ, Arend WP, et al. Interleukin1 receptor antagonist activity of a human interleukin-1 inhibitor. Nature 1990; 343: 336-340.

5. Eisenberg SP, Evans RJ, Arend WP, et al. Primary structure and functional expression from complementary DNA of a human interleukin-1 receptor antagonist. Nature 1990; 343: 341-346.

6. Arend WP, Joslin FG, Thompson RC, Hannum CH. An IL-1 inhibitor from human monocytes: production and characterization of biologic properties. J Immunol 1989; 143: 1851-1858.

7. Arend WP, Welgus HG, Thompson RC, Eisenberg SP. Biological properties of recombinant human monocytederived interleukin-1 receptor antagonist. J Clin Invest 1990; 85: 1694-1697.

8. Sone S, Orino E, Mizuno K, et al. Production of IL-1 and its receptor antagonist is regulated differently by IFN$\gamma$ and IL-4 in human monocytes and alveolar macrophages. Eur Respir J 1994; 7: 657-663.

9. Moore SA, Strieter RM, Rolfe MW, Standiford TJ, Burdick MD, Kunkel SL. Expression and regulation of human alveolar macrophage-derived interleukin-1 receptor antagonist. Am J Respir Cell Mol Biol 1992; 6: 569-575.

10. Kline JN, Monick MM, Hunninghake GW. IL-1 receptor antagonist release is regulated differently in human alveolar macrophages than in monocytes. J Appl Physiol 1992; 73: 1686-1692.

11. Colotta F, Peri G, Villa A, Mantovani A. Rapid killing of actinomycin D-treated tumor cells by human mononuclear cells. I. Effectors belong to the monocyte-macrophage lineage. J Immunol 1984; 132: 936-944.

12. Yanagawa $\mathrm{H}$, Sone $\mathrm{S}$, Nii A, et al. Lymphokine-activated killer induction and its regulation by macrophages 
in malignant pleural effusions. Jpn J Cancer Res 1989; 80: $1220-1227$.

13. Watanabe N, Kamei S, Ohkubo A, et al. Urinary protein as measured with a pyrogallol red-molybdate complex, manually and in a Hitachi 726 automated analyzer. Clin Chem 1986; 32: 1551-1554.

14. Ribera E, Ocana I, Martinez-Vazquez JM, Rossell M, Esponol T, Ruibal A. High level of interferon gamma in tuberculous pleural effusion. Chest 1988; 93: 308-311.

15. Wewers MD, Rennard SI, Hence AJ, Bitterman PB, Crystal RG. Normal human alveolar macrophages obtained by bronchoalveolar lavage have a limited capacity to release interleukin-1. J Clin Invest 1984; 74: 22082218.

16. Hart PH, Ahern MJ, Jones CA, Jones KL, Smith MD, Finlay-Jones JJ. Synovial fluid macrophages and blood monocytes differ in their responses to IL-4. J Immunol 1993; 151: 3370-3380.

17. Gjomarkaj M, Pace E, Melis M, Spatafora M, Toews GB. Mononuclear cells in exudative malignant pleural effusions: characterization of pleural phagocytic cells. Chest 1994; 106: 1042-1049.

18. Knopf HP, Otto F, Engelhardt R, et al. Discordant adaptation of human peritoneal macrophages to stimulation by lipopolysaccharide and the synthetic lipid A analogue SDZ MRL 953. J Immunol 1994; 153: 287-299.

19. McColl SR, Paquin R, Menard C, Beaulieu AD. Human neutrophils produce high levels of the interleukin-1 receptor antagonist in response to granulocyte/macrophage colony-stimulating factor and tumor necrosis factor- $\alpha$. $J$ Exp Med 1992; 176: 593-598.
20. Smith DR, Kunkel SL, Standiford TJ, et al. The production of interleukin-1 receptor antagonist by human bronchogenic carcinoma. Am J Pathol 1993; 143: 794-803.

21. Berger HW, Mejia E. Tuberculous pleurisy. Chest 1973; 63: 88-92.

22. Shiratsuchi H, Tsuyuguchi I. Analysis of T-cell subsets by monoclonal antibodies in patients with tuberculosis after in vitro stimulation with purified protein derivative of tuberculin. Clin Exp Immunol 1984; 57: 271-278.

23. Barnes PF, Mistry SD, Cooper CL, Rea TH, Modlin RL. Compartmentalization of a CD4+ T-lymphocyte subpopulation in tuberculous pleuritis. J Immunol 1989; 142: 1114-1119.

24. Onozaki K, Matsushima K, Aggarwal BB, Oppenheim JJ. Human interleukin-1 is a cytocidal factor for several tumor cell lines. J Immunol 1985; 135: 3962-3967.

25. Chirivi RGS, Garofalo A, Padura IM, Mantovani A, Giavazzi R. Interleukin-1 receptor antagonist inhibits the augmentation of metastasis induced by interleukin-1 or lipopolysaccharide in a human melanoma/nude mouse system. Cancer Res 1993; 53: 5051-5054.

26. de Waal Malefyt R, Abrams J, Bennet B, Figdor CG, de Vries JE. Interleukin-10 (IL-10) inhibits cytokine synthesis by human monocytes: an autoregulatory role of IL-10 produced by monocytes. J Exp Med 1991; 174: 1209-1220.

27. Yanagawa H, Sone S, Haku T, et al. Contrasting effect of interleukin-13 on production of interleukin-1 receptor antagonist and proinflammatory cytokines by human alveolar macrophages. Am J Respir Cell Mol Biol 1995; 12: 71-76. 